PLPB : Pendidikan Lingkungan dan Pembangunan Berkelanjutan

DOI : http://doi.org/10.21009/PLPB.182.03

DOI $: 10.21009 /$ PLPB

\title{
PENGARUH EXPERIENTIAL LEARNING DAN PENGETAHUAN PEMBANGUNAN BERKELANJUTAN TERHADAP BERPIKIR ANALITIK MASALAH LINGKUNGAN
}

\author{
Eva Marthinu ${ }^{1}$, Nadiroh ${ }^{2}$ \\ ${ }^{1}$ Program Studi Pendidikan Geografi FKIP Universitas Khairun Ternate \\ Jl. Batu Angus, Kel. Dufa-Dufa, Kota Ternate Utara \\ Email:eva.marthinu@yahoo.com \\ ${ }^{2}$ Fakultas Ilmu Sosial Universitas Negeri Jakarta, \\ Komplek Universitas Negeri Jakarta Gedung M. Hatta Jl. Rawamangun Muka, \\ Jakarta Timur, Indonesia 13220 \\ Orchid Id: 0000-0001-9807-2536, Sinta ID: 6003834 \\ Email:nadiroh@unj.ac.id
}

\begin{abstract}
This study aims at investigating effects of experiential learning strategy and knowledge of sustainable development concept toward students' analytical thinking ability about environmental issues. An experimental method with $2 \times 2$ factorial design was employed in this quantitative study which was conducted at SMA Negeri 3 Ternate. Samples of the study were 52 students of grade IX of Social Sciences selected by means of random sampling. Data analysis shows that: 1. In general, students using experiential learning strategy with outdoor approach have higher average score on analytical thinking ability about environmental issues than those with indoor approach, 2. Students having high knowledge level in sustainable development concept and using outdoor approach have higher average score on analytical thinking ability about environmental issues than those with indoor approach, 3. Students having low knowledge level in sustainable development concept and using indoor approach have higher average score on analytical thinking ability about environmental issues than those with outdoor approach, 4. There are significant interaction effects between experiential learning strategy and knowledge of sustainable development concept toward students analytical thinking ability about environmental issues.
\end{abstract}

Keywords: experiential learning strategy, sustainable development, analytical thinking ability, environmental issues

\begin{tabular}{|l|l|l|l|}
\hline Volume XVIII & Nomor 2 & September 2017 & ISSN 1411-1829 \\
\hline
\end{tabular}




\section{PENDAHULUAN}

Harapan agar terwujud lingkungan yang memiliki daya dukung dan kualitas yang dapat mendukung kehidupan kini dan bagi generasi yang akan dating sesuai dengan yang diamanatkan dalam UU RI No.32 tahun 2009 tentang Perlindungan dan Pengelolaan Lingkungan Hidup pasal 1 ayat 3 bahwa pembangunan berkelanjutan adalah upaya sadar dan terencana yang memadukan aspek lingkungan hidup, sosial, dan ekonomi ke dalam strategi pembangunan untuk menjamin keutuhan lingkungan hidup serta keselamatan, kemampuan, kesejahteraan, dan mutu hidup generasi masa kini dan generasi masa depan, maka hidup serasi dengan alam sekitar, dengan sesama manusia, dan dengan Tuhan Yang Maha Esa, selalu diajarkan pada kita.

Siswa-siswi pada Sekolah Menengah Atas di kota Ternate Utara khususnya di SMA Negeri 3 merupakan bagian dari masyarakat kota Ternate, seharusnya memiliki tanggung jawab yang sama dalam menjaga keberlanjutan daya dukung dan kualitas lingkungan, namun pada kenyataannya belum semuanya menunjukkan sikap dan tanggung jawab sebagai implementasi dari kemampuan berpikir analitik tentang masalah lingkungan yang menjadi salah satu tujuan dari pembelajaran materi pembangunan berkelanjutan yang sudah dipelajarinya. Kebiasaan membuang sampah sembarangan, tidak ikut ambil bagian merawat tanaman di halaman sekolah (dibiarkan tak terurus), kebiasaan merusak tanaman di taman atau trotoar, membiarkan lampu menyalah pada siang hari, tidak menutup kran sesudah menggunakan air, dinding dan meja tulis yang tercoret-coret, membuang ludah sembarangan, kamar mandi dan kamar kecil yang tidak terjaga kebersihannya dan tak jarang terlihat coretan-coretan yang tidak mendidik, menyimpan sampah dilaci meja, dll, semua itu merupakan indikator sikap dan perilaku yang kurang kompeten sebagai cerminan rendahnya kemampuan berpikir analitik tentang masalah lingkungan.

Penerapan strategi dan pendekatan pembelajaran yang kurang melibatkan siswa secara fisik maupun emosi, kurang melatih dan membiasakan serta menyentuh sikap dan kemampuan berpikir analitik siswa dalam melihat permasalahan lingkungan di sekitar kehidupannya, membuat siswa kurang peka dan akhirnya tidak merasa memiliki masalah yang merujuk pada tidak sikap peduli dan bertanggung jawab. Hal ini menjadi salah satu pemicu masalah di

\begin{tabular}{|l|l|l|l|}
\hline Volume XVIII & Nomor 2 & September 2017 & ISSN 1411-1829 \\
\hline
\end{tabular}


atas yang perlu dicari solusinya untuk perbaikan pembelajaran ke depan demi perubahan pola pikir, sikap dan perilaku siswa itu sendiri agar mampu berperan dalam melihat masalah lingkungan sebagai penerapan pengetahuan tentang lingkungan, terutama tentang konsepkonsep pembangunan berkelanjutan yang sudah diperolehnya pada pembelajaran sebelumnya. Salah satu strategi pembelajaran yang relevan dengan maksud ini adalah strategi pembelajaran experiential learning dengan pendekatan outdoor.

Pengetahuan tentang konsep pembangunan berkelanjutan adalah merupakan variabel yang mempengaruhi perbedaan kemampuan siswa menganalisis masalah lingkungan. Oleh karena itu, maka menarik untuk diteliti mengenai aspek kemampuan berpikir analitik siswa Sekolah Menengah Atas (SMA) tentang masalah lingkungan yang merupakan bagian dari pembelajaran geografi, sebagai implementasi dari pengetahuan tentang konsep pembangunan berkelanjutan yang dilakukan melalui penerapan strategi pembelajaran experiential learning dengan pendekatan pembelajaran yang mempunyai relevansinya dalam pencapaian kemampuan berpikir analiik tentang masalah lingkungan.
Sejalan dengan maksud di atas, Anderson dan Krathwohl (2010) mengatakan bahwa menganalisis adalah melibatkan proses memecah-mecah materi jadi bagian-bagian kecil dan menentukan bagaimana hubungan antar bagian dan antara setiap bagian dan struktur keseluruhannya. Kategori proses menganalis ini meliputi proses-proses kognitif membedakan, mengorganisasi, dan mengatribusikan.Berpikir analitik adalah kemampuan untuk memeriksa dan memecah fakta dan pikiran menjadi kekuatan dan kelemahan. Mengenai Masalah lingkungan menurut Chiras (1991) adalah berkaitan secara umum dengan apapun di sekeliling atau sekitar manusia, yaitu udara, air dan tanah, termasuk didalamnya tanaman, hewan segala komponen yang hidup dan tidak hidup, interaksi antara sesama komponen.

Kemampuan berpikir analitik siswa tentang masalah lingkungan perlu latihan dan pembiasaan. Untuk mencapai tujuan ini, dibutuhkan strategi pembelajaran yang dapat memberikan pembiasaan kemerdekaan berpikir dan berpendapat kepada anak didik untuk mampu mencari alternatif solusi masalah. Salah satu strategi yang dianggap tepat dan relevan dengan tujuan ini adalah strategi pembelajaran experiential

\begin{tabular}{|l|l|l|l|}
\hline Volume XVIII & Nomor 2 & September 2017 & ISSN 1411-1829 \\
\hline
\end{tabular}


learning (experiential learning strategies).

David Kolb (1999) dalam teori experiential learning mendefinisikan belajar sebagai proses dimana pengetahuan diciptakan melalui transformasi pengalaman. Pengetahuan merupakan kombinasi dari memperoleh dan mengubah pengalaman. Pendapat senada dikemukakan oleh Lewis \& Williams (1994) yang mengatakan bahwa experiential learning adalah metode penyajian pembelajaran dimana siswa belajar dengan melakukan, dan menerapkan pengetahuan dan pengalaman untuk mengembangkan keterampilan atau cara berpikir yang baru.

Upaya menanamkan kebiasaan menganalisis berbagai persoalan lingkungan, selain dibutuhkan strategi pembelajaran yang sesuai, juga suatu pendekatan pembelajaran yang dapat memberikan pengalaman nyata pada siswa, agar apa yang dipelajari relevan dengan masalah yang dihadapi dalam kehidupan sehari-hari. Oleh karena itu pendekatan pembelajaran di luar kelas atau dikenal dengan outdoor merupakan pendekatan pembelajaran yang dianggap tepat untuk tujuan tersebut.

Wolsk (1997) mengatakan bahwa pembelajaran dengan pendekatan outdoor adalah pendekatan pengalaman langsung, dimana murid dihadapkan pada pengalaman langsung dengan pengamatan dilapangan (outdoor teaching), kemudian mencatat dan membuat laporannya. Selanjutnya Keith Brown (2010) mengatakan bahwa belajardi luar ruangandapat memberikanpendidikanpembangunan berkelanjutanmelalui inisiatif sepertibekerja untuk meningkatkankeanekaragaman hayatidi lingkungansekolah, mengunjungihutansetempat, menjelajahidan terlibatdengan masyarakatlokal danmengembangkan rencanaperjalanansekolah.

Berbeda dengan pendekatan outdoor, Pembelajaran dengan pendekatan indoor menurut Wolsk (1997) adalah murid melakukan aktivitas seperti membaca buku teks, mendengarkan tape, menonton film, dsb di dalam ruang kelas (indoor teaching). Murid diminta mereproduksikan dalam berbagai bentuk, misalnya karangan deskriptif. Model pembelajaran pertemuan di dalam kelas ini menurut William Glasser (2009) terdiri atas enam tahap, yaitu: (1) menciptakan iklim suasana yang kondusif); menyampaikan permasalahan diskusi; (3) membuat penilaian pribadi;

\begin{tabular}{|l|l|l|l|}
\hline Volume XVIII & Nomor 2 & September 2017 & ISSN 1411-1829 \\
\hline
\end{tabular}


mengidentifikasi tindakan solusi; (5) membuat komitmen; (6) merencanakan tindak lanjut tindakan.

Kemampuan berpikir analitik mengenai berbagai persoalan hidup terkait dengan penguasaan sejumlah informasi dalam hal ini pengetahuan yang tepat dan relevan sebab pengetahuan tentang isu atau masalah merupakan syarat awal untuk memulai suatu tindakan yang tepat.

Jujun (2009) mengatakan bahwa pengetahuan merupakan sesuatu yang sangat penting, karena pengetahuan adalah sumber jawaban bagi berbagai pertanyaan yang muncul dalam kehidupan.Obyek pengetahuan dalam penelitian ini adalah konsep tentang pembangunan berkelanjutan. Menurut Eldon dan Badley (2008) konsep pembangunan berkelanjutan pertama kali dicetuskan oleh World Commission Environment and Development (WCED), suatu badan yang dibentuk oleh PBB. Dalam tahun 1987, WCED membuat laporannya yang berjudul "Our Common Future," diangkat isu pembangunan berkelanjutan (sustainable development) yang didefinisikan sebagai pembangunan yang ditujukan untuk memenuhi kebutuhan generasi sekarang tanpa mengorbankan kemampuan generasi mendatang untuk memenuhi kebutuhan mereka sendiri.

Penelitian ini bertujuan untuk mengetahui:1). Perbedaan kemampuan berpikir analitik tentang masalah lingkungan antara siswa yang mengikuti strategipembelajaran experiential learning dengan pendekatan outdoor dan pendekatan indoor, 2). Perbedaan kemampuan berpikir analitik tentang masalah lingkungan antara siswa yang memiliki tingkat pengetahuan tentang konsep pembangunan berkelanjutan tinggi, yang mengikuti strategi pembelajaran experiential learning dengan pendekatan outdoor dan pendekatan indoor, 3). Perbedaan kemampuan berpikir analitik tentang masalah lingkungan antara siswa yang memiliki tingkat pengetahuantentang konsep pembangunan berkelanjutan rendah,yang mengikuti strategi pembelajaran experiential learning dengan pendekatan outdoor dan pendekatan indoor, 4). Pengaruh interaksi antara strategi pembelajaran experiential learning dan pengetahuan tentang konsep pembangunan berkelanjutan terhadap kemampuan berpikir analitik siswa tentang masalah lingkungan.

\begin{tabular}{|l|l|l|l|}
\hline Volume XVIII & Nomor 2 & September 2017 & ISSN 1411-1829 \\
\hline
\end{tabular}




\section{METODOLOGI PENELITIAN}

Teknik penentuan sampel dilakukan secara bertahap dengan menggunakan multi stage random yaitu : 1).Dari seluruh SMA Negeri yang ada di kota Ternate, terpilih secara cluster random SMA Negeri 3 Kota Ternate, 2).Penentuan secara purposive kelas XI IPS yang berjumlah 4 kelas, untuk menetapkan kelas mana yang dijadikan sebagai kelas eksperimen dan kelas mana sebagai kelas kontrol, oleh peneliti, 3). Dari hasil tersebut, dipilih secara cluster random dua kelas dari empat kelas XI IPS, dimana satu kelas sebagai kelas strategi pembelajaran berbasis masalah dengan pendekatan outdoor (A1) dan yang satu kelasnya lagi sebagai kelas strategi pembelajaran berbasis masalah dengan pendekatan indoor (A2), 4).Seluruh siswa kelas eksperimen terdiri dari 40 orang siswa dan kelas kontrol terdiri dari 40 orang siswa, yang selanjutnya diberikan tes untuk mengukur pengetahuan tentang konsep pembangunan berkelanjutan. Hasil atau skor masing - masing siswa diurutkan, 5). Penentuan besarnya sampel pada masing - masing kelas penelitian, diambil dari $33 \%$ siswa untuk tiap kelompok. Dari hasil tersebut akan diperoleh 13 orang dengan perolehan skor pengetahuan tentang konsep pembangunan berkelanjutan tertinggi, dan 13 orang dengan perolehan skor pengetahuan tentang konsep pembangunan berkelanjutan terendah, baik untuk kelas strategi pembelajaran berbasis masalah dengan pendekatan outdoor maupun strategi pembelajaran berbasis masalah dengan pendekatan indoor. Jadi secara keseluruhan sampel berjumlah 52 orang siswa.

Ada dua jenis instrumen yang digunakan dalam penelitian ini yakni bentuk tes digunakan untuk mengumpulkan data pengetahuan tentang konsep pembangunan berkelanjutan dan rating scale untuk mengumpulkan data kemampuan berpikir analitik siswa tentang masalah lingkungan. Hasil pengolahan data variabel kemampuan berpikir analitik tentang masalah lingkungan untuk uji validitas terhadap 30 orang responden dan dengan alpha $(\alpha)$ $=0,05$, maka diperoleh $\mathrm{r}_{\text {tabel }}$ sebesar 0,36 . Sedangkan untuk mengukur reliabilitasnya kriteria yang dipakai adalah dengan membandingkan antara hasil $r_{\text {alpha }}$ dengan $r_{\text {tabel}}$, apabila hasilnya positif dan lebih besar dari $\mathrm{r}$ tabel, maka varibel-variabel yang digunakan reliabel dengan nilai Alpha Cronbach yang diperoleh adalah sebesar 0,811. Untuk menguji validitas dari pengetahuan tentang konsep pembangunan

\begin{tabular}{|l|l|l|l|}
\hline Volume XVIII & Nomor 2 & September 2017 & ISSN 1411-1829 \\
\hline
\end{tabular}


berkelanjutan adalah Hasil pengolahan data untuk uji validitas terhadap 30 orang responden dan dengan alpha $(\alpha)=0,05$, maka diperoleh $r_{\text {tabel }}$ sebesar 0,444 . Nilai Alpha Cronbach yang diperoleh adalah sebesar 0,910 .

\section{HASIL DAN PEMBAHASAN}

Berdasarkan hasil analisis varian dua jalur pada taraf signifikan $\alpha=0,05$, didapat $\mathrm{F}_{\text {hitung }}=4,85$ dan $\mathrm{F}_{\text {tabel }}=4,04$. Dengan demikian $F_{\text {hitung }}>F_{\text {tabel }}$, sehingga $\mathrm{H}_{\mathrm{o}}$ ditolak. Dapat disimpulkan bahwa secara keseluruhan, terdapat perbedaan yang nyata antara strategi pembelajaran experiental learning dengan pendekatan outdoor dengan pendekatan indoor terhadap kemampuan berpikir analitik siswa tentang masalah lingkungan. Dengan perkataan lain bahwa strategi pembelajaran experiental learning dengan pendekatan outdoor $(\bar{X}=41,92$; $\mathrm{S}=11,40$ ) lebih baik dari pada dengan pendekatan indoor $(\bar{X}=39,54 ; \mathrm{S}=$ 9,56). Terdapat perbedaan sebesar 41,92$39,54=2,38$. Ini berarti hipotesis penelitian yang menyatakan bahwa secara keseluruhan strategi pembelajaran experiental learning dengan pendekatan outdoor lebih baik dibanding dengan pendekatan indoor diterima. Hal ini terbukti berdasarkan hasil uji lanjut dalam analisis varian dua jalur dengan menggunakan uji Tukey yang hasilnya dapat dilihat pada tabel 2 :

Tabel 2.

Perbandingan Kelompok $\mathrm{A}_{1}$ dan $\mathrm{A}_{2}$

\begin{tabular}{|l|l|l|l|l|}
\hline No & Kelompok yang & \multirow{2}{*}{$\begin{array}{l}\text { q } \\
\text { Dibandingkan }\end{array}$} & quatung & \multicolumn{2}{|l|}{} \\
\cline { 4 - 5 } & & & $\boldsymbol{\alpha}=\mathbf{0 , 0 5}$ & $\boldsymbol{\alpha}=\mathbf{0 , 0 1}$ \\
\hline 1 & $\mathrm{~A}_{1}$ dengan $\mathrm{A}_{2}$ & $3,09 *$ & 2,91 & 3,93 \\
\hline
\end{tabular}

Siswa yang memiliki pengetahuan tentang konsep pembangunan berkelanjutan tinggi memberikan pengaruh terhadap kemampuan berpikir analitik siswa tentang masalah lingkungan dengan menggunakan strategi pembelajaran berbasis masalah dengan pendekatan outdoor. Hal ini terbukti berdasarkan hasil uji lanjut dalam analisis varian dengan menggunakan uji Tukey yang hasilnya dapat dilihat pada tabel 3 :

Tabel 3.

Perbandingan Kelompok $\mathrm{A}_{1} \mathrm{~B}_{1}$ dengan $\mathrm{A}_{2} \mathrm{~B}_{1}$

\begin{tabular}{|l|l|l|l|l|}
\hline \multirow{2}{*}{ No } & Kelompok & yang & \multirow{2}{|c|}{$\mathbf{q}_{\text {tabel }}$} \\
\cline { 4 - 5 } & Dibandingkan & & $\begin{array}{l}\text { q }= \\
\text { hitung }\end{array}$ & $\begin{array}{l}\boldsymbol{\alpha}= \\
\mathbf{0 , 0 1}\end{array}$ \\
\hline 2 & $\mathrm{~A}_{1} \mathrm{~B}_{1}$ dengan & 19,88 & 4,15 & 5,40 \\
& $\mathrm{~A}_{2} \mathrm{~B}_{1}$ & $* *$ & & \\
\hline
\end{tabular}

$\begin{array}{lcr}\text { Siswa } & \text { yang } & \text { memiliki } \\ \text { pengetahuan } & \text { tentang } & \text { konsep } \\ \text { pembangunan } & \text { berkelanjutan } & \text { rendah } \\ \text { memberikan } & \text { pengaruh } & \text { terhadap } \\ \text { kemampuan } & \text { berpikir analitik } & \text { siswa }\end{array}$

\begin{tabular}{|l|l|l|l|}
\hline Volume XVIII & Nomor 2 & September 2017 & ISSN 1411-1829 \\
\hline
\end{tabular}


tentang masalah lingkungan bila mengikuti strategi pembelajaran experiental learning dengan pendekatan indoor. Hal ini terbukti berdasarkan hasil uji lanjut dalam analisis varian dengan menggunakan uji Tukey yang hasilnya dapat dilihat pada tabel 4:

Tabel 4.

Perbandingan KelompokA $\mathrm{A}_{1}$ dengan $\mathrm{A}_{2} \mathrm{~B}_{2}$

\begin{tabular}{|l|l|l|l|l|}
\hline \multicolumn{5}{|c|}{ Nengan $\mathrm{A}_{2} \mathrm{~B}_{2}$} \\
\hline \multirow{2}{*}{ No } & Kelompok & yang & q & \multicolumn{2}{|l|}{$\mathbf{q}_{\text {tabel }}$} \\
\cline { 4 - 5 } & Dibandingkan & & $\boldsymbol{\alpha}=\mathbf{0 , 0 5}$ & $\begin{array}{l}\boldsymbol{\alpha} \\
\mathbf{0 , 0 1}\end{array}$ \\
\hline 3 & $\mathrm{~A}_{1} \mathrm{~B}_{2}$ dengan & 15,45 & 4,15 & 5,40 \\
& $\mathrm{~A}_{2} \mathrm{~B}_{2}$ & $* *$ & & \\
\hline
\end{tabular}

Berdasarkan hasil analisis varian dua faktor pada tabel perhitungan anava di atas menunjukkan bahwa harga hitung $\mathrm{F}_{\text {hitung }}$ interaksi $=310,23$ dan $\mathrm{F}_{\text {tabel }}=$ 7,016. Tampak bahwa fungsi $F_{\text {hitung }}>$ $\mathrm{F}_{\text {tabel, }}$ sehingga Ho ditolak. Kesimpulannya bahwa terdapat interaksi antara strategi pembelajaran experiential learning dengan pengetahuan tentang konsep pembangunan berkelanjutan terhadap kemampuan berpikir analitik siswa tentang masalah lingkungan.

Hasil perhitungan ANAVA dua faktor tersebut menunjukkan bahwa kelompok siswa yang menggunakan strategi pembelajaran experiental learning dengan pendekatan outdoor memiliki skor kemampuan berpikir analitik tentang masalah lingkungan ratarata sebesar 41,92. Sedangkan kelompok siswa yang menggunakan strategi pembelajaran experiental learning dengan pendekatan indoor memiliki skor kemampuan berpikir analitik tentang masalah lingkungan rata-rata sebesar 39,54. Kelompok siswa yang memiliki pengetahuan tentang konsep pembangunan berkelanjutan tinggi mempunyai skor kemampuan berpikir analitik tentang masalah lingkungan ratarata sebesar 41,88. Sedangkan Kelompok siswa yang memiliki pengetahuan tentang konsep pembangunan berkelanjutan rendah mempunyai skor kemampuan berpikir analitik tentang masalah lingkungan rata-rata sebesar 39,58 .

Berdasarkan uji ANAVA dua faktor ini menunjukkan bahwa kemampuan berpikir analitik tentang masalah lingkungan bagi siswa yang memperoleh strategi pembelajaran experiental learning dengan pendekatan outdoor lebih tinggi dibanding dengan pendekatan indoor, dan kemampuan berpikir analitik tentang masalah lingkungan bagi siswa yang memiliki pengetahuan tentang konsep pembangunan berkelanjutan tinggi yang memperoleh strategi pembelajaran experiental learning dengan pendekatan

\begin{tabular}{|l|l|l|l|}
\hline Volume XVIII & Nomor 2 & September 2017 & ISSN 1411-1829 \\
\hline
\end{tabular}


outdoor lebih tinggi daripada dengan pendekatan indoor. Sebaliknya siswa yang memiliki pengetahuan tentang konsep pembangunan berkelanjutan rendah yang memperoleh strategi pembelajaran experiental learning dengan pendekatan indoor lebih tinggi daripada dengan pendekatan outdoor.

Agar lebih jelas, dapat dilihat melalui grafik interaksi antara strategi pembelajaran berbasis masalah dan pengetahuan tentang konsep pembangunan berkelanjutan pada gambar 1 berikut ini :

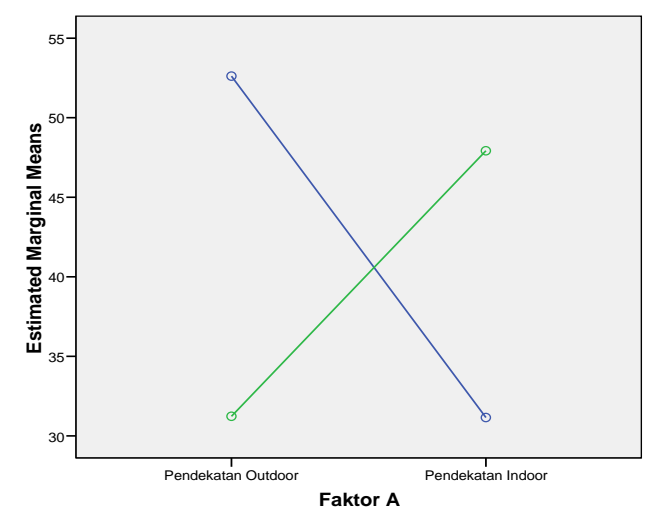

Gambar 1

Estimated Marginal Means Kemampuan Berpikir Analitis Siswa tentang Masalah Lingkungan

Hipotesis pertama. Secara keseluruhan, terdapat perbedaan kemampuan berpikir analitik siswa tentang masalah lingkungan yang mengikuti strategi pembelajaran experiental learning melalui pendekatan outdoor dibandingkan dengan pendekatan indoor
Berdasarkan hasil analisis varian (ANAVA) dua jalan pada pengujian hipotesis 1 ditemukan bahwa $\mathrm{F}_{\text {hitung }}$ lebih besar dari $\mathrm{F}_{\text {tabel }}\left(\mathrm{F}_{\text {hitung }}=4,85>\right.$ $\left.\mathrm{F}_{\text {tabel }(0,05)(1 ; 48)}=4,04\right)$. Ini menunjukkan bahwa terdapat perbedaan yang signifikan kemampuan berpikir analitik siswa tentang masalah lingkungan antara kelompok siswa yang memperoleh strategi pembelajaran experiental learning dengan pendekatan outdoor dengan pendekatan indoor. Perbedaan ini ditunjukkan pula dengan nilai rata-rata kemampuan berpikir analitik siswa tentang masalah lingkungan dari kedua pendekatan tesebut (outdoor dan indoor) pada strategi pembelajaran experiental learning dengan selisih rata-rata sebesar $41,92-39,54=2,38$. Selanjutnya untuk mengetahui kelompok data yang memiliki rerata yang signifikan, maka dilanjutkan dengan uji Tuckey, dimana hasil uji ditemukan bahwa $\mathrm{q}_{\text {hitung }}=3,09$ > $\mathrm{q}_{\text {tabel(0,05)(2;26) }}=2,91$. Hal ini berarti bahwa rata-rata kemampuan berpikir analitik siswa tentang masalah lingkungan yang memperoleh strategi pembelajaran experiental learning dengan pendekatan outdoor lebih tinggi dari kelompok yang memperoleh strategi pembelajaran experiental learning dengan pendekatan indoor.

\begin{tabular}{|l|l|l|l|}
\hline Volume XVIII & Nomor 2 & September 2017 & ISSN 1411-1829 \\
\hline
\end{tabular}


Jadi kesimpulannya, dari kedua pendekatan pada strategi pembelajaran experiental learning baik pendekatan outdoor maupun indoor, sama-sama memberikan kontribusi pada peningkatan kemampuan berpikir analitik tentang masalah lingkungan, namun tetap berbeda kontribusinya secara signifikan, dimana pendekatan outdoor lebih memiliki keunggulan dibandingkan pendekatan indoor. Hal ini sesuai dengan pendapat dari Collin Beard (2006) bahwa experiential learning dapat diterapkan di dalam kelas (indoor) dan di luar kelas (outdoor), di lingkungan alamiah (nature) dan di lingkungan buatan (artificial). Selanjutnya dipertegas oleh Anonymous yang mengatakan bahwa Pembelajaran di luar kelas (outdoor) memiliki kelebihan dibandingkan dengan pembelajaran di dalam kelas (indoor). Pembelajaran di dalam kelas menimbulkan masalah kurangnya keterlibatan indra perasa dalam memahami fenomena yang ada di lingkungan alamiah. Sedangkan pembelajaran di luar kelas siswa menggunakan lebih banyak indra mereka untuk belajar di lingkungannya. Faktor inilah menunjukkan perbedaan yang terjadi antara kedua pendekatan tersebut signifikan.

Hipotesis Kedua, terdapat perbedaan kemampuan berpikir analitik tentang masalah lingkungan bagi siswa yang memiliki pengetahuan tentang konsep pembangunan berkelanjutan tinggi yang memperoleh strategi pembelajaran experiental learning melalui pendekatan outdoor dibandingkan dengan pendekatan indoor. Hasil uji Tuckey pada pengujian hipotesis 2 menunjukkan bahwa siswa yang memiliki pengetahuan tentang konsep pembangunan berkelanjutan tinggi, yang diberi strategi pembelajaran experiential learning dengan pendekatan outdoor nilai $\mathrm{q}_{\text {hitung }}=19,88$ lebih besar dari $\mathrm{q}_{\text {tabel }(0,05)(4 ; 13)}=4,15$. Hal ini berarti bahwa terdapat perbedaan kemampuan berpikir analitik siswa tentang masalah lingkungan pada kelompok siswa yang memperoleh strategi pembelajaran experiential learning dengan pendekatan outdoor dan pendekatan indoor untuk kelompok siswa yang memiliki pengetahuan tentang konsep pembangunan berkelanjutan tinggi. Dengan demikian dapat disimpulkan bahwa pada kelompok siswa yang memiliki pengetahuan tentang konsep pembangunan berkelanjutan tinggi, ratarata skor kemampuan berpikir analitik siswa tentang masalah lingkungan yang mengikuti strategi pembelajaran experiential learning dengan pendekatan outdoorlebih tinggi dari kelompok siswa

\begin{tabular}{|l|l|l|l|}
\hline Volume XVIII & Nomor 2 & September 2017 & ISSN 1411-1829 \\
\hline
\end{tabular}


dengan pendekatan indoor. Hal ini dapat dilihat dari kemampuan berpikir analitik tentang masalah lingkungan pada siswa yang memiliki pengetahuan tentang konsep pembangunan berkelanjutan tinggi yang memperoleh strategi pembelajaran experiential learning dengan pendekatan outdoor lebih baik dibandingkan melalui pendekatan indoor. Hal ini terjadi karena melalui strategi pembelajaran experiential learning outdoor pada siswa dengan pengetahuan pembangunan berkelanjutan tinggi, lebih merangsang kemampuannya dalam mengeksplor pengetahuan awal yang telah dimiliki dan mengaitkannya dengan fakta dari masalah yang menjadi obyek kajian pembelajaran di lapangan sehingga melahirkan inspirasi untuk memperoleh jawaban penyebab masalah dan memiliki banyak ide untuk mendapatkan alternatif solusi masalah dan mampu mengevaluasi solusi terbaik dari yang baik untuk dipilih secara mandiri melalui pemikiran analitis. Pada siswa dengan pengetahuan pembangunan berkelanjutan rendah yang memperoleh strategi pembelajaran experiential learning outdoor, memiliki kemandirian yang kurang dalam mengeksplor ide-ide alternatif solusi sehingga kurang analitis dalam memilih solusi terbaik dari masalah yang dikaji karena kurangnya bekal pengetahuan yang relevan dengan masalah tersebut. Sedangkan pada siswa dengan pengetahuan pembangunan rendah yang memperoleh strategi pembelajaran experiential learning indoor, kemampuan berpikir untuk mengeksplor ide-ide alternatif solusi masalah yang sedang dikaji lebih baik karena lebih banyak bantuan arahan dari guru dalam memfasilitasi pola pikirnya untuk menemukan informasi masalah melalui berbagai sumber, baik cetak maupun elektronik, walaupun ide solusinya tidak setepat dibandingkan dengan kelompok dengan pengetahuan pembangunan berkelanjutan tinggi yang diajar dengan strategi pembelajaran experiential learning outdoor.

Hal ini sejalan dengan pendapat Brown (2010) yang mengatakan bahwa belajardi luar ruangandapat memberikan pendidikan pembangunan berkelanjutan melalui inisiatif sepertibekerja untuk meningkatkan keanekaragaman hayati di lingkungan sekolah, mengunjungi hutan setempat, menjelajahi dan terlibat dengan masyarakat lokal dan mengembangkan rencana perjalanans ekolah. Bahkan saat ini yang sangat favorit untuk dilakukan adalah sekolah hutan, di mana mereka mengambil piknik makan siang, mereka bisa bermain, mengeksplorasi dan menyelidiki semua hal yang ada di hutan

\begin{tabular}{|l|l|l|l|}
\hline Volume XVIII & Nomor 2 & September 2017 & ISSN 1411-1829 \\
\hline
\end{tabular}


sekolah tersebut. Siswa benar-benar sangat menikmati proses pembelajaran yang seperti itu karena belajar sambil rekreasi, sehingga tidak membosankan. Lebih lanjut Anderson dan krathwoll (2010) mengatakan bahwa pengetahuan digunakan dalam setiap kemampuan dan ketrampilan, karena penggunaan kemampuan dan ketrampilan yang efektif, membutuhkan pengetahuan yang tepat.

Hipotesis ketiga, Terdapat perbedaan kemampuan berpikir analitik tentang masalah lingkungan bagi siswa yang memiliki pengetahuan tentang konsep pembangunanberkelanjutan rendah, yang memperoleh strategi pembelajaran experiential learning melalui pendekatan outdoor dibandingkan dengan pendekatan indoor. Adapun hasil uji Tuckey pada pengujian hipotesis 3 , kelompok siswa yang memiliki pengetahuan tentang konsep pembangunan berkelanjutan rendah yang diberi strategi pembelajaran experiential learning dengan pendekatan indoor diperoleh nilai $\mathrm{q}_{\mathrm{hitung}}=15,45$ lebih besar dari $q_{\text {tabel(}(0,05)(4 ; 13)}=4,15$. Hal ini berarti bahwa terdapat perbedaan kemampuan berpikir analitik siswa tentang masalah lingkungan pada kelompok siswa dengan pengetahuan tentang konsep pembangunan berkelanjutan rendah, yang memperoleh strategi pembelajaran experiential learning dengan pendekatan outdoor dan indoor. Dengan demikian dapat disimpulkan bahwa pada kelompok siswa yang memiliki pengetahuan tentang konsep pembangunan berkelanjutan rendah, rata-rata skor kemampuan berpikir analitik siswa tentang masalah lingkungan pada kelompok siswa yang memperoleh strategi pembelajaran experiential learning dengan pendekatan indoorlebih tinggi daripada kelompok pendekatan outdoor.

Hal ini dapat dilihat dari kemampuan berpikir analitik tentang masalah lingkungan pada siswa yang memiliki pengetahuan tentang konsep pembangunan berkelanjutan rendah yang memperoleh strategi pembelajaran experiential learning dengan pendekatan indoor lebih baik dibandingkan melalui pendekatan outdoor. Hal ini terjadi karena melalui strategi pembelajaran experiential learning indoor pada siswa dengan pengetahuan pembangunan berkelanjutan rendah, lebih diarahkan sistematika berpikirnya melalui bimbingan dari guru dalam menemukan informasi-informasi yang relevan dengan masalah yang sedang dibahas. Hal ini sangat penting karena dengan minimnya pengetahuan tentang konsep

\begin{tabular}{|l|l|l|l|}
\hline Volume XVIII & Nomor 2 & September 2017 & ISSN 1411-1829 \\
\hline
\end{tabular}


pembangunan berkelanjutan, menyebabkan siswa tersebut minim ide untuk secara mandiri mencari alternatif solusi masalah dan lemah dalam menganalisis konsekuensi dari penentuan keputusan yang diambilnya untuk solusi tersebut. Oleh karena itu, siswa tersebut perlu tuntunan dalam kegiatan belajarnya dan pendekatan yang tepat adalah belajar di dalam kelas (indoor).

Hal ini sesuai dengan apa yang dikemukakan oleh Solso bahwa pengetahuan adalah sekumpulan informasi yang disusun secara teratur. Akan tetapi pengetahuan yang tidak banyak akan membatasi kemampuan pemahaman karena pembaca harus mengembangkan bangunan pengetahuan mengenai materinya serta menerjemahkan informasi yang dibacanya. Pendapat ini mengisyaratkan bahwa jika seseorang minim pengetahuan maka memiliki keterbatasan kemampuan berpikir analitik tentang masalah lingkungan karena untuk sampai pada taraf berpikir analisis, terlebih dahulu harus melewati taraf berpikir yang mengingat, memahami, mengaplikasikan. Bagaimana siswa bisa menganalisis suatu masalah jika tidak mengenal dan memahami masalahnya? Oleh karena itu, tingkat pengetahuan dalam hal ini pengetahuan tentang konsep pembangunan berkelanjutan sangat penting dalam menunjang kemampuan berpikir analitik siswa tentang masalah lingkungan.

Hipotesis keempat. Terdapat pengaruh interaksi yang sangat signifikan antara strategi pembelajaran experiential learning dan pengetahuan tentang konsep tentang pembangunan berkelanjutan terhadap kemampuan berpikir analitik siswa tentang masalah lingkungan. Berdasarkan hasil analisis varian (ANAVA) dua jalan pada pengujian hipotesis 4 ditemukan bahwa $F_{\text {hitung }}$ interaksi $\mathrm{AB}$ lebih besar dari $\mathrm{F}_{\text {ta bel }}\left(\mathrm{F}_{\text {hitung }}\right.$ $\left.=310,23>\mathrm{F}_{\text {tabel }(0,05)(1 ; 51)}=7,16\right)$. Hal ini berarti bahwa terdapat pengaruh interaksi yang sangat signifikan antara strategi pembelajaran experiential learning dan pengetahuan tentang konsep pembangunan berkelanjutan terhadap kemampuan berpikir analitik siswa tentang masalah lingkungan. Hal ini sesuai dengan pendapat Lewis \& Williams (1994) bahwa experiential learning adalah metode pemberian pembelajaran dimana siswa belajar dengan melakukan, dan menerapkan pengetahuan dan pengalaman untuk mengembangkan keterampilan atau cara berpikir yang baru

$$
\text { Jelaslah bahwa untuk }
$$
meningkatkan kemampuan berpikir

\begin{tabular}{|l|l|l|l|}
\hline Volume XVIII & Nomor 2 & September 2017 & ISSN 1411-1829 \\
\hline
\end{tabular}


analitik siswa tentang masalah lingkungan dibutuhkan pengetahuan tentang konsep pembangunan yang berkelanjutan sebagai bekal untuk lebih banyak memperoleh gagasan-gagasan, ide dan bisa mengevaluasi konsekwensi dari pengambilan keputusan. Namun pengetahuan yang dimiliki tidak akan berkontribusi dengan baik dan hanya akan bersifat potensial, jika tidak ditunjang dengan penerapan strategi dan pendekatan pembelajaran yang sesuai.

\section{KESIMPULAN}

Terdapat pengaruh antara strategi pembelajaran experiential learning dan pengetahuan tentang konsep pembangunan berkelanjutan terhadap kemampuan berpikir analitik siswa tentang masalah lingkungan. Hal ini berarti untuk meningkatkan kemampuan berpikir analitik siswa tentang masalah lingkungan maka harus mempertimbangkan strategi pembelajaran dan pengetahuan yang relevan bagi siswa, dimana bagi yang memiliki pengetahuan tentang konsep pembanguanan berkelanjutan tinggi maka lebih baik jika diberi strategi pembelajaran experiential learning dengan pendekatan outdoor. Sebaliknya jika pengetahuan tentang konsep pembangunan siswa rendah maka sebaiknya diberi strategi pembelajaran experiential learning dengan pendekatan indoor.

\section{DAFTAR PUSTAKA}

Anderson Lorin\& Krathwohl David, R. p. 2010. Kerangka Landasan Untuk Pengajaran dan Asesmen Revisi Taksonomi Pendidikan Bloom. Yogyakarta: Pustaka Pelajar.

Beard Collin., W. P. 2006. Experiential learning, second edition. London: British Library cataloging in publication Data.

Keith, B. 2010. Curriculum excellence Through Outdoor Learning. Scotland: Improving Scottish Education.

Chiras, R. 1991. Environment Science Action For a Sustainable Future. California : Cumming Publishing Company Inc, .

Smith, E. E. 2008.Environmental Science A Study of Interelationship Elevent Edition. McGraw-Hill International Edition Higher Education.

E.Richard, K. A. 1999. Experiential learning Theory: Previous Research and New Directions. Western: Reserve University.

Lewis L.H., \&. C. ( 1994). Experiential learning: A New Approach. San Francisco: Jossey-Bas.

Pierce, J. W. (n.d.). Problem Based Learning : Learning and Teaching in The Context of Problem. Illinois: Northern Illinois University.

\begin{tabular}{|l|l|l|l|}
\hline Volume XVIII & Nomor 2 & September 2017 & ISSN 1411-1829 \\
\hline
\end{tabular}


Annie, R. (2015). Synthesizing the Outdoor Education. University of Wyoming.

Suriasumantri, J. S. ( 2009). Filsafat Ilmu, sebuah pengantar populer. Jakarta: Pustaka Sinar Harapan.

Robert, S. (1991). Cognitive Psychology. Boston: Allya and Bacon.

Wolsk David, G. J. (1997). Metodologies of Environmental Education: Trends in Environmental Education.

Undang-Undang RI No. 32 Tahun 2009 (2010). tentang perlindungan dan pengelolaan lingkungan hidup. Jakarta: kementerian lingkungan hidup.

\begin{tabular}{|l|l|l|l|}
\hline Volume XVIII & Nomor 2 & September 2017 & ISSN 1411-1829 \\
\hline
\end{tabular}

